\title{
Total Quality Management for Information Systems in Saudi Firms
}

\author{
Osama Islam \\ King Abdulaziz University \\ Facility of Computing and \\ Information Technology \\ Jeddah, Saudi Arabia
}

\author{
Yousef Baoum \\ King Abdulaziz University \\ Facility of Computing and \\ Information Technology \\ Jeddah, Saudi Arabia
}

\author{
Syed Hamid Hasan \\ King Abdulaziz University \\ Facility of Computing and \\ Information Technology \\ Jeddah, Saudi Arabia
}

\begin{abstract}
Purpose. Saudi Arabian firms have grown throughout the years from simple manually run operations to highly sophisticated operations with complex Information Systems (IS). However, not all firms that acquire information systems are able effectively align it with their business objectives or utilize it to streamline critical processes within their firms. In addition, simple IS-focused process improvement initiatives lack the comprehensiveness needed to align IS with business objectives. As a result, an increasing number of organizations have implemented TQM as a means to enhancing all processes, including IS ones, to achieve lasting improvements in organizations. This research study aims to better understand the interrelated link that TQM and IS may have to support the achievement of effective IT-Business alignment.
\end{abstract}

Approach/ Procedure. A survey questionnaire was used for data collection, which was addressed to top IT/IS Managers in Saudi firms. The sample was selected at random, with the main selection criteria for participants been that they work at a Saudi firm. In addition, the number of respondents were 6 out of a total of 20 invites sent to companies to participant in the research.

Findings/ Results. Interestingly the findings show that TQM is a well-known concept, even though most do not have a lot of experience in implementing TQM. In particular, the TQMIS relationship was viewed to be beneficial specifically to obtaining greater customer satisfaction and enhancing the quality of delivered products/ services. On the other hand, cost cutting and enhancing IS personnel productivity was not highly perceived as a benefit from using TQM with IS. In addition, both customer centric and benchmarking were perceived as strongly highlighting the successful aspects of TQM implementations.

Applied Inferences. The findings indicated a general ability for TQM to enhance IS in supporting the firm's external and internal customers. In addition, even though top management support was rated as highly supporting TQM, customer centric and benchmarking were also perceived as critical parts needed for effective TQM. This implies that firms identify and believe that TQM is a valuable tool for improvement in customer satisfaction and most of them look for ways to adapt it within their firm (either within IS or other areas of the firm).

Objectivity. The research study was limited to a small sample of Saudi firms, which was selected at random, as a result there may be some degree of bias in respondent's answers. However, in general the research study provided overall findings that can be further researched and analyzed in the future.

\section{General Terms}

Information Systems, Management of Computing and Information Systems, Computing and Business.

\section{Keywords}

Total Quality Management, Information Systems, Saudi Arabia.

\section{INTRODUCTION}

Total Quality Management (TQM) as explained by (Besterfield et al., 2003) is the utilization of various measureable methods and personnel to enhance all business processes in an organization with the overall goal of exceeding customer expectation currently and in the future. This concept has gained attention from organizations around the world as quality has become one of the main criteria for customers when buying products and services. As a result, TQM can help organizations achieve higher profits, improved productivity and lower costs if it is implemented in a comprehensive manner.

At the same time, adopting TQM within information system departments and functions is also important, given the critical nature that information systems play in today's online and real-time business operations. Information systems also provide a mechanism for achieving TQM as it affects most functions within an organization and can be a positive enabler for quality/ customer focused transformation initiatives.

\subsection{TQM Outlines}

As a management concept TQM enables organizations to seek increased profits by focusing on delivering quality products and services, which leads to increased market share and customer base, while avoiding the overhead costs of rework and waste of low quality business processes (Deming, 1986). To better outline TQM a number of principles have been proposed by various authors across the years, the following are five of these key principles (Anderson, Rungtusanatham, \& Schroeder, 1994), (Dean \& Bowen, 1994) and (Waldman, 1994): 


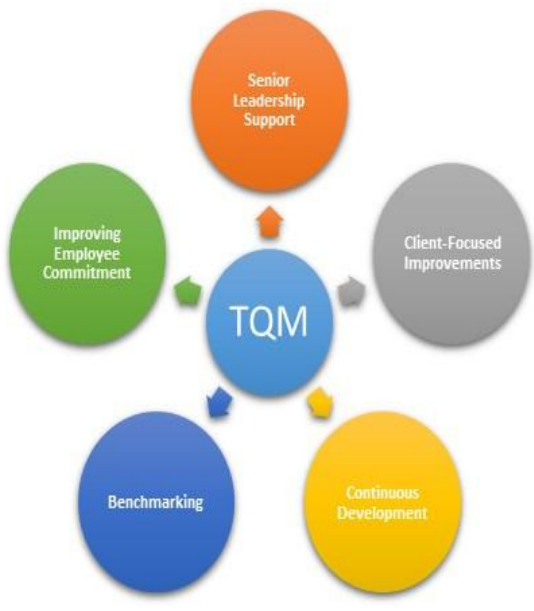

Figure 1: Key Principles of TQM

\subsubsection{Senior Leadership Support}

This is a critical component of any successful TQM program, as senior management must not only support and provide funding for such project but they also need to show strong leadership with a focus on quality.

\subsubsection{Client-Focused Improvements}

The organization must clearly identify its customer both internally and externally and then systematically work on ensuring their satisfaction and continuous interaction with them to obtain feedback.

\subsubsection{Continuous Development}

A TQM project must be supported by a culture that seeks to continuously find ways to improve business processes, as a result, process owners must learn to implement problemsolving methods to identify, analyze and implement opportunities for process improvements as part of their daily routine.

\subsubsection{Benchmarking}

This component also seeks to improve processes but from a variance control perspective, by adapting quality standards and then measuring its adherence using techniques such as statistical process control, Pareto charts, and others.

\subsubsection{Improving Employee Commitment}

Human resources are an instrumental component of TQM programs as they can make or break its successful implementation, as a result, focus must be placed on training and educating employees in organizations to ensure they are effectively motivated and engaged in the TQM program.

\subsection{TQM with Respect to IS}

Although the interrelated links that TQM and IS have were explored by a number of research studies, most focus on one more than the other (Barata \& Cunha, 2015), which highlights that both are important for effective improvement in organizations. At the same time, as separate disciplines both TQM and IS have traditionally different techniques and methodologies to introduce improvements in organizations and are conducted as separate projects.

Therefore, if organizations want to benefit from their information systems function, they must move from the traditional thinking of IS being a tool for improved productivity to the thinking that IS is an instrumental part of delivering quality products to customers and increasing customer satisfaction.
TQM if implement correctly can assist IS in raising their contributions to the delivery of quality products to customers and achieving organizational objectives (Carroll \& Swatman, 1997), by focusing on quality and continuous improvement, building a positive culture that focuses on quality, team spirit, and clear communication between IS personnel and management.

\section{MOTIVATION}

The research study strives to highlight the potential that TQM can have on improving IS as an integral part of Saudi organizations. This is especially important with the increasing number of failures in implementing information systems that meet their user requirements. In addition, to the misunderstandings that IS personnel may have with TQM, which is seen as a management practice not related to their IT/IS function (Zadrozny \& Tumanic, 1992).

\section{AIMS}

The research study aims to investigate the following key areas of TQM and IS in Saudi firms:

- The level of experience in using TQM within IS functions.

- The degree of assistance that senior management provides to TQM implementations that includes the IS function.

- The degree of realized value from implementing TQM.

- The implemented aspects of TQM.

- The link between TQM-IS realized value and senior management assistance.

- The link between TQM-IS realized value and the implemented aspects of TQM.

\section{SCOPE AND RANGE}

The Saudi market has traditionally been dependent on Oil revenues and government spending to spur market growth, however in recent years' privatization, globalization and diversification of industries has opened up the Saudi market for high competition by not only local organizations but also international ones. Customers is the Saudi market have gotten used to higher levels of quality expected from international organizations, which has applied increased pressure on Saudi firms to meet this demand or lose market share.

As a result, more Saudi firms have started to adapt quality programs that helps them ensure increased quality standards in their products and services. However, most of these quality programs are not as effective as expected as they require the involvement of key functions rather than been an outsider program that reviews standards. One of the key functions that such programs needs is the information system function, as it provides both the systems that supports the firm's operations and the mechanism to measuring quality standards.

\section{METHODOLOGY}

A number of studies were utilized (Cheon \& Stylianou, 2001), (Rahman \& Siddiqui, 2006) to assist in designing the survey questionnaire to collect the needed information for the study. The questions were provided in form of statements that respondents had to answer by selecting one of the options in a Likert scale. 
The survey questionnaire was addressed to top IT/IS Managers in Saudi firms. The sample was selected at random, with the main selection criteria for participants been that they work at a Saudi firm. In addition, the number of respondents were 6 out of a total of 20 invites sent to companies to participant in the research. The final responses were then used in the analysis of the research study.

\section{FINDINGS}

\subsection{Knowledge of TQM by IT/IS Managers}

As highlighted in table 1 the majority of respondents indicated that they are aware of TQM. In particular, their understanding of the detail aspects of TQM was varied ranging from $66.7 \%$ with little to somewhat understanding and $33.3 \%$ who understand very much the concepts of TQM. This highlights the fact that based on the sample TQM is mostly a known concept however there are either IT/IS managers with very good knowledge of TQM or ones with very limited knowledge. On the other hand, $83.4 \%$ of respondents saw that TQM has little to somewhat effect on IS with only $16.7 \%$ seeing TQM having much effect on IS. This indicates that there are still some misconceptions on the role that TQM can play within the domain of IS.

Table 1. Knowledge of TQM by IT/IS Managers

\begin{tabular}{|l|l|l|l|l|l|}
\hline Question & Answer & \multicolumn{2}{|l|}{ Numbers } & \multicolumn{2}{l|}{ Percentage } \\
\hline $\begin{array}{l}\text { TQM is known } \\
\text { to Manager }\end{array}$ & Yes & 5 & 6 & $83.3 \%$ & $100 \%$ \\
\hline & No & 1 & & $16.7 \%$ & \\
\hline $\begin{array}{l}\text { Understand } \\
\text { TQM Aspects }\end{array}$ & Very Much & 2 & 6 & $33.3 \%$ & $100 \%$ \\
\hline & Much & 0 & & $0 \%$ & \\
\hline & Somewhat & 3 & & $50 \%$ & \\
\hline & A Little & 1 & & $16.7 \%$ & \\
\hline $\begin{array}{l}\text { Idea of the } \\
\text { effect of TQM } \\
\text { on IS }\end{array}$ & Very Little & 0 & & $0 \%$ & \\
\hline & Much & 0 & 6 & $0 \%$ & $100 \%$ \\
\hline & Somewhat & 4 & & $66.6 \%$ & \\
\hline & A Little & 1 & & $16.7 \%$ & \\
\hline & Very Little & 0 & & $0 \%$ & \\
\hline
\end{tabular}

\subsection{Degree of Experience in using TQM in IS}

In reference to the degree of experience in using TQM the majority of respondents had very little experience with less than one year, with exceptional cases of more than that. This reflects that most IT/IS managers are either not involved in TQM projects or that the companies they worked for did not implement TQM at all. When compared to previous answers related to their awareness of TQM it seems that most respondents have at least heard and are aware of the concept of TQM but did not get a chance to use or adapt it in their daily work routines.
Table 2. Degree of Experience in using TQM in IS

\begin{tabular}{|l|l|l|l|l|l|}
\hline Question & Answer & \multicolumn{2}{|l|}{ Numbers } & \multicolumn{2}{|l|}{ Percentage } \\
\hline $\begin{array}{l}\text { Degree of } \\
\text { Experience in } \\
\text { using TQM in } \\
\text { IS }\end{array}$ & Less than 1 & 4 & 6 & $66.6 \%$ & $100 \%$ \\
\hline & $1-3$ & 1 & & $16.7 \%$ & \\
\hline & $3-5$ & 0 & & $0 \%$ & \\
\hline & Above 5 & 1 & & $16.7 \%$ & \\
\hline
\end{tabular}

\subsection{Values of TQM for IS}

When analyzing the responses to the questions related to the benefits of TQM use with IS, the highest identified benefit and value from respondents was the excepted enhanced quality of delivered products, followed by both expected improvements to customer satisfaction and improvements in the effectiveness of personnel utilization. Such results indicate that most of respondents perceive TQM as benefiting the external aspects of the firm such as the end-products and customer relationships.

Table 3. Values of TQM for IS

\begin{tabular}{|l|l|l|}
\hline Question & Mean & $\begin{array}{l}\text { Standard } \\
\text { Deviation }\end{array}$ \\
\hline $\begin{array}{l}\text { Reducing Costs of maintaining } \\
\text { business applications }\end{array}$ & 3.1667 & 1.6749 \\
\hline Raised control of IS management & 3.3333 & 1.1055 \\
\hline Excellent service quality & 4.1667 & 0.6871 \\
\hline Improved satisfaction of Customers & 4.3333 & 0.9428 \\
\hline Improved productivity of IS staff & 3.8333 & 0.8975 \\
\hline Improved time of production & 3.8333 & 0.6871 \\
\hline $\begin{array}{l}\text { Enhanced quality of delivered } \\
\text { products }\end{array}$ & 4.5000 & 0.7637 \\
\hline Effective Utilization of Personnel & 4.3333 & 0.7453 \\
\hline $\begin{array}{l}\text { Ability to Reach Customer is } \\
\text { multiple ways }\end{array}$ & 4.1667 & 0.8975 \\
\hline
\end{tabular}

\subsection{Degree of Adapted TQM Aspects}

In reference to analyzing the degree of adapting TQM principles and aspects, the highest principle identified by respondents were continuous enhancement/ improvement, in addition to benchmarking. On the other hand, improvements to customer focus was also perceived as an implementable aspect of TQM.

Table 4. Degree of Adapted TQM Aspects

\begin{tabular}{|l|l|l|}
\hline Question & Mean & $\begin{array}{l}\text { Standard } \\
\text { Deviation }\end{array}$ \\
\hline Improvements in customer focus & 4.1667 & 1.0671 \\
\hline Continuous Enhancement & 4.3333 & 0.4714 \\
\hline Increasing Employee Commitment & 4.0000 & 1.1547 \\
\hline Benchmarking & 4.3333 & 0.7453 \\
\hline
\end{tabular}




\begin{tabular}{|ll|l|l|}
\hline Question & & Mean & $\begin{array}{l}\text { Standard } \\
\text { Deviation }\end{array}$ \\
\hline $\begin{array}{l}\text { Assistance from Senior } \\
\text { Management }\end{array}$ & & 4.0000 & 0.5773 \\
\hline
\end{tabular}

\subsection{Link between Senior Management and TQM Values}

The majority of respondents $(83.3 \%)$ clearly identified that TQM obtains support from top or senior management. This is supported by the fact that TQM is usually presented as a management practice or improvement program and as such is introduced from top-down as a way to achieve company goals.

Table 5. Link between Senior Management and TQM Values

\begin{tabular}{|l|l|l|l|l|l|}
\hline Question & Answer & \multicolumn{2}{|l|}{ Numbers } & \multicolumn{2}{|l|}{ Percentage } \\
\hline $\begin{array}{l}\text { TQM for IS } \\
\text { gets support } \\
\text { from senior } \\
\text { management }\end{array}$ & High & 5 & 6 & $83.3 \%$ & $100 \%$ \\
\hline & Low & 1 & & $16.7 \%$ & \\
\hline
\end{tabular}

\subsection{Link between Implemented Aspects of TQM and TQM Values}

In analyzing the relationship between the implemented aspects and values of TQM both benchmarking and improvements in customer focus were identified as high factors. This supports previous responses of benchmarking being an important aspect of TQM, while customer focus is indirectly supported with the benefit of customer satisfaction.

Table 6. Link between Implemented Aspects of TQM and TQM Values

\begin{tabular}{|l|l|l|}
\hline Question & Mean & $\begin{array}{l}\text { Standard } \\
\text { Deviation }\end{array}$ \\
\hline Relentless improvement & 4.0000 & 1.0000 \\
\hline Benchmarking & 4.5000 & 0.7637 \\
\hline Improvements in customer focus & 4.5000 & 0.5000 \\
\hline Conviction of top management & 4.1667 & 0.6871 \\
\hline Strengthening of employee base & 3.8333 & 1.0671 \\
\hline
\end{tabular}

\section{DISCUSSIONS}

\subsection{Limitations}

The research study was limited to a small sample of people who represent Saudi firms, and were selected at random, as a result there may be some degree of bias in respondent's answers or opinions and the current research does not take into account possible differences in opinion within a particular firm. In addition, some of the questions assume a degree of comprehension in terms of what is meant by TQM as a concept, as a result, there may also be some degree of variances in the definitions of TQM that each respondent knows.

\subsection{Universal Applicability}

The research study was conducted in Saudi Arabia, which is still considered a developing economy and as such its findings cannot be universally applied to any country in the world. However, in general the research study provided overall findings that can be further researched and analyzed in any specific country to determine varying differences that a culture may have on TQM and IS relationships.

\subsection{Previous Work and its Compliance}

In reviewing previous work, a majority of literature, such as (Hua, Chin, \& Xu, 2000) and (Howard \& Foster, 1999), indicate similar findings that senior management support is critical TQM implementations. In addition, similar to (Pearson, McCahon, \& Hightower, 1995) current findings also indicate that IT/IS personnel in Saudi firms still face challenges in understanding TQM or have the readiness to implement it in an effective manner.

\section{CONCLUSIONS}

Based on the results of the research, we can conclude that the awareness of TQM for IS in Saudi firms has increased given the high responses of IT/IS managers who have heard of TQM. In addition, the majority identified the potential of TQM effect on IS, however it was not highly rated as expected but this may be due to their limited experience in using TQM, which was overall less than one year. Therefore, such findings may indicate a raising trend that TQM is becoming a familiar concept in Saudi firms who seek key benefits such as increased satisfaction of clients, enhancement of product quality, and the utilization of IS personnel.

On the other hand, when exploring TQM principles Saudi firms focus more on benchmarking and continuous improvement more than other aspects of TQM. In addition, based on the analysis of supporting factors senior management commitment was clearly identified as a critical component for successful TQM implementation in Saudi firms. At the same time, it is important to note that the strengthening of employee base, which is an important concept in TQM implementations, was not highly rated as a supporting factor to TQM by Saudi firms, such a perception may indicate a degree of misunderstanding of the role of TQM.

\section{ACKNOWLEDGMENTS}

Our sincere thanks goes to Professor Syed H. Hasan for his guidance and support in completing this research study.

\section{REFERENCES}

[1] Anderson, J., Rungtusanatham, M., \& Schroeder, R. (1994). A theory of quality management underlying the Deming management method. Academy of Management Review, 19(3), 472-509.

[2] Barata, J., \& Cunha, P. R. (2015). Synergies between quality management and information systems: a literature review and map for further research. Total Quality Management \& Business Excellence, 1-14.

[3] Besterfield, D. H., Besterfield-Michna, C., Besterfield, G. H., Besterfield-Sacre, M., Urdhwareshe, H., \& Urdhwareshe, R. (2003). Total Quality Management. Pearson Education India.

[4] Carroll, J., \& Swatman, P. (1997). Total quality management for information systems: the Australians experience. In Proceedings of 8th Australian Conference on Information Systems.

[5] Cheon, M. J., \& Stylianou, A. C. (2001). Total quality management for information systems: an empirical 
investigation. Journal of Global Information Technology Management, 4(4), 32-5.

[6] Dean, J. W., \& Bowen, D. E. (1994). Management theory and total quality: improving research and practice through theory development. Academy of Management Review, 19(3), 392-418.

[7] Deming, W. E. (1986). Out of the Crisis. MIT Press, Cambridge, MA.

[8] Howard, L. W., \& Foster, S. T. (1999). The influence of human resource practices on empowerment and employee perceptions of management commitment to quality. Journal of Quality Management, 4(1), 5-32.

[9] Hua, H., Chin, K. S., \& Xu, Y. (2000). An empirical study on quality management practices in Shanghai manufacturing industries. Total Quality Management, 11(8), 1111-2.
[10] Pearson, J. M., McCahon, C. S., \& Hightower, R. T. (1995). Total quality management: are information system mangers ready? Information \& Management, 29, $252-63$.

[11] Rahman, Z., \& Siddiqui, J. (2006). Exploring total quality management for information systems in Indian firms. Business Process Management Journal, 12(5), 622-631.

[12] Waldman, D. A. (1994). The contributions of total quality management to a theory of work performance. Academy of Management Review, 19(3), 510-36.

[13] Zadrozny, M. A., \& Tumanic, R. E. (1992). Zero-defects software: the total quality management approach to software engineering. Chief Information Officer Journal, 4(4), 10-6. 